\title{
Liberando ecos: una propuesta metodológica contrahegemónica, colectiva y performática para la construcción de una dignidad en resistencia
}

Liberando Ecos: A Methodological, Counterhegemonic, Colective and Performative Proposal for the Construction of a Dignity in Resistance

Liberando ecos: uma proposta metodológica contra-hegemónica, coletiva e performática para a construção de uma dignidade em resistência

Círculo Literario Vertedero Satélite ${ }^{1}$

Esteban Alfaro Orozco ${ }^{2}$

Sebastián Barquero Zúñiga ${ }^{3}$

Silvia Elena Guzmán Sierra ${ }^{4}$

Marcelo Valverde Morales 5

1 El Círculo Literario Vertedero Satélite está compuesto por Esteban Alfaro Orozco, Sebastián Barquero Zúñiga, Silvia Elena Guzmán Sierra y Marcelo Valverde Morales. Las cuatro personas se dedican a la investigación, gestión e innovación en ciencias sociales, artes y gestión cultural. https://vertederosatelite.wordpress.com/ resena-de-trabajo/

2 Psicólogo, Asistente Académico IDESPO - UNA.

3 Politólogo, Asistente Académico CIEP - UCR.

4 Internacionalista, Asistente Académica - IDELA - UNA.

5 Internacionalista, Asistente Académico - IDELA - UNA. 


\section{Resumen}

El presente documento es la revisión teórico metodológica postvivencial del proyecto: Promoción de las artes literarias en el Centro Penitenciario Sandoval de Limón: liberando ecos (2016). Esta revisión pretende delimitar metodológica y teóricamente los aportes del Círculo Literario Vertedero Satélite, para la construcción de dignidades en resistencia a través de una concepción del arte contrahegemónica, colectiva y performática.

\section{Palabras clave:}

Cuerpo-dignificante, educación no formal, población privada de libertad, poesía

\section{Summary}

The present document is the post-experiential theoretical-methodological revision of the Literary Arts Promotion Project at the Sandoval de Limón Penitentiary Center: Liberando Ecos (2016). This review aims to delimit methodologically and theoretically the contributions of the Circulo Literario Vertedero Satelite for the construction of dignities in resistance through a counter hegemonic, collective and performative conception of art.

Keywords: Body-dignifying, Non-formal education, Population deprived of freedom, Poetry

\section{Resumo}

O presente documento é a revisão teórico-metodológica pós-vivencial do projeto Promoção das Artes Literárias do Centro Penitenciário Sandoval de Limón: Liberando Ecos (2016). Esta revisão pretende delimitar metodológica e teoricamente as contribuições do Círculo Literario do Aterro Satélite para a construção de dignidades em resistência por meio de uma concepção de arte contra hegemônica, coletiva e performática.

Palavras chave: Corpo dignificante, Educação não formal, População privada de liberdade, Poesia

\section{Introducción}

Dignidad y resistencia son dos palabras que deben ser tomadas en cuenta en el mundo de lo práctico, más allá de lo simbólico y lo discursivo. Dos sustantivos con necesidad de ser verbo, a través de la creatividad y los usos que los sujetos pueden dar a sus significaciones. Este trabajo pretende dar a conocer el análisis teórico y metodológico postvivencial de una experiencia que se construyó como una de las formas posibles de hacer arte que sea crítica y dignificadora. Por tanto, pretende compartir las aportaciones teóricas del colectivo de gestión cultural Círculo Literario Vertedero Satélite (CLVS) en el desarrollo de una metodología para la construcción participativa de una dignidad psicosocial en resistencia. Esta metodología se fundamenta en la experiencia del proyecto: Promoción de las artes literarias en el Centro Penitenciario Sandoval de la provincia de Limón, Costa Rica: liberando ecos. 
Esta es además una metodología transdisciplinar que se sustenta en un quehacer performático, contrahegemónico y colectivo del CLVS, así como en las teorías decoloniales, los feminismos, las teorías críticas de los derechos humanos, la sociometría, la educación no formal, y la estética crítica. Transdisciplinar, también en el entendido de que las subjetividades de cada uno de los integrantes del círculo son, en una pretensión abstracta, un cúmulo de conocimientos científicos, filosóficos y culturales que se yuxtaponen para la creación de la metodología aquí presentada.

Por otro lado, es importante resaltar la importancia del cuerpo como concepto transversal en la propuesta, el cual no sería solo la materialización de la persona, sino la persona misma, no hay separación entre el ser y el cuerpo. Se introduce el concepto de Cuerpo-Dignificante como un sujeto histórico que carga en sí mismo en el nivel discursivo y estético un sin número de violencias simbólicas y por tanto, cargas sociales en la manifestación de su ser físico. Un cuerpo-dignificante es aquel que reconoce estas violencias a las cuales ha sido sometido sistemáticamente y a partir de ellas se reivindica para hacer visibles sus diferencias y las de aquellas personas con quienes se relaciona para, a partir de esta diversidad crear alternativas.

\section{El proyecto Liberando Ecos: la poesía como herramienta para la transformación social}

\subsection{Origen de la iniciativa}

CLVS surge del encuentro de un equipo facilitador compuesto por jóvenes interesados en el arte literario y la intervención e interacción social a través de ello. Como antecedente común compartían la experiencia de haber participado en el Taller Literario de la Universidad Nacional, iniciativa estudiantil independiente surgida en el año 2010.

Durante los años en los cuales los facilitadores formaron parte de este taller, organizaron diferentes recitales en espacios universitarios y comunitarios. Además, trabajaron con diversas poblaciones vulnerabilizadas, tales como grupos de personas con cuidados paliativos, jóvenes, grupos migrantes y adultos mayores, llevando a diferentes espacios el compartir literario.

Cada una de las personas facilitadoras que forman el Circulo Literario gestor del proyecto, cuenta con experiencia en la participación de iniciativas artístico-sociales que les han llevado de manera colectiva a la idea de trasmitir la poesía a más poblaciones. 
Es por ello, que se presenta el proyecto, como una forma de compartir no solamente la literatura, sino también la creación literaria y la publicación, con una población que particularmente no tendría la oportunidad de hacerlo.

\subsection{Objetivos y metas propuestas}

El proyecto denominado: Promoción de las artes literarias en el Centro Penitenciario Sandoval de Limón: liberando ecos, pretendió rescatar y promulgar el patrimonio artístico y cultural de las personas privadas de libertad, en el recinto penitenciario Sandoval de Limón, también aprender conjuntamente las numerosas formas de expresión escrita y artística inmersas en la creación poética, con el fin último de brindarles la oportunidad de ser publicados en un libro como portadores de una voz creativa.

Analógicamente, la experiencia vivida por los integrantes de CLVS y los participantes de la población beneficiada, fue plasmada mediante los poemas surgidos en el proceso de aprendizaje conjunto, se concluyó con la visibilización de los esfuerzos y los encuentros colectivos en torno a la expresión y la creación poética, desde una diversidad de sensibilidades, perspectivas e historias de vida.

El proyecto se compuso de tres objetivos específicos, el primero de ellos es: desarrollar laboratorios participativos de creación y expresión literaria con población penitenciaria, para la producción de textos de carácter vivencial - artístico de las personas participantes. De dicho objetivo se desprende respectivamente, la fase de los laboratorios de creación, dentro de la cual se desarrolla actividades dirigidas al conocimiento de este arte, para llevar a cabo en consecución, ejercicios de creación literaria, por parte de los participantes, facilitando un proceso de revisión y autoedición, propios de un taller.

El segundo objetivo del proyecto corresponde a: editar los textos producidos en los laboratorios a fin de la constitución estética del producto final, del cual se desprende correspondientemente, la fase de edición del material literario. Comprende además la edición filológica, la construcción y el diseño artístico del producto final, el cual consiste en un libro colectivo que presenta los poemas producidos por los participantes del proceso.

El tercer objetivo responde a: publicar los textos editados a fin de visibilizar la experiencia vivida, para este objetivo se realizó una fase de publicación y promoción del producto final, para alcanzar dicha meta, se realizaron actividades tales como el tiraje de los ejemplares del producto final (libro colectivo), la visualización en 
medios de comunicación y la presentación, tanto en el centro penal, como en espacios culturales.

\subsection{Período de ejecución}

El proyecto tuvo una duración de ocho meses y se dividió en tres etapas: (1) laboratorios de creación literaria (marzo a agosto 2016). (2) Edición del material literario (setiembre 2016). (3) Publicación y promoción del producto final (octubre-noviembre 2016).

\subsection{Metodología}

El proyecto se desarrolló con los privados de libertad del Centro Penitenciario Sandoval de Limón, en el Caribe costarricense, que se encontraban cursando alguna carrera universitaria de la Universidad Estatal a Distancia (UNED), en el mes de marzo del 2016. Se planteó una metodología participativa en donde la interacción vivencial de las partes (Círculo Literario Vertedero Satélite, población penitenciaria, público meta) es el núcleo metodológico.

\section{a) Laboratorios de creación literaria}

En esta primera fase, el Círculo Literario Vertedero Satélite trabajó junto con las personas privadas de libertad en la experimentación a través de ejercicios lúdicos de creación poética. Esta fase tiene una duración de 6 meses, una sesión al mes de cuatro horas cada día. A su vez se divide en tres partes:

- Conocimiento: este primer momento se planteaba como un espacio de identificación con la poesía, en el cual se intentaba llevar a los participantes a un acercamiento de las diferentes técnicas y estilos del quehacer literario, así como también, una introducción a las formas metodológicas lúdicas de aprender haciendo y aprender jugando.

- Creación: en este segundo momento se planteaba un proceso participativo de creación literaria, en el cual los colaboradores podían experimentar diferentes ejercicios de estimulación y así, obtener como resultado composiciones literarias. En esta etapa los participantes tendrían como tarea la creación individual de textos literarios, fuera del espacio de los laboratorios.

- Revisión: el objetivo de la primera fase fue la construcción del producto final, por lo que se planteó una primera edición y revisión colectiva de los escritos durante los laboratorios, para afinar detalles estéticos y definir cuáles eran los textos por publicar. 
b) Edición del material literario

Una vez finalizados los laboratorios fue responsabilidad del Círculo Literario Vertedero Satélite junto con la editorial contactada, emprender el proceso de edición del libro por publicar. En esta etapa, se contempla la edición filológica, así como los aspectos estéticos referentes al arte. El diseño del libro tomó en cuenta las experiencias y las opiniones de los participantes de los laboratorios. Esta etapa comprendió aproximadamente un mes.

c) Publicación y promoción del producto final

La fase final del proyecto tuvo el objetivo de visibilizar la experiencia vivida y estuvo a cargo del Círculo Literario Vertedero Satélite, la editorial contactada y del Programa de la Defensoría Estudiantil UNED. Se compuso de tres momentos: 1. El tiraje de los ejemplares. 2. La visualización del proyecto en medios de comunicación (radio, televisión y prensa escrita de circulación nacional). 3. Dos recitales uno en el Centro Penitenciario Sandoval de Limón y otro en el espacio cultural la Casona Iluminada en San José.

\section{La experiencia resultante del proyecto Liberando Ecos}

Con la finalización de este proyecto el CLVS realizó una sistematización de la experiencia, con el objetivo de rescatar los aprendizajes teóricos, a partir del proceso de dignificación vivido por los participantes, se consideraron tres razones justificantes: (1) obtener y rescatar los descubrimientos y los aprendizajes teórico metodológicos, (2) recuperar la experiencia de aprendizaje colectivo o proceso de facilitación de un espacio formativo, y por último (3) determinar los descubrimientos que se obtuvieron en el nivel metodológico, con el fin de establecer parámetros conceptuales y prácticos para aplicar en propuestas futuras.

Los ámbitos de las experiencias en los cuales se pretende ahondar son: (1) relación objetivos planteados-resultados obtenidos, donde nos preguntamos: ise cumplió en la realidad lo que decía el papel? (2) la facilitación: ¿cuál es el rol del facilitador de un proyecto de gestión cultural en un centro penitenciario? (3) el grupo como plataforma para escribir: ¿cuál es el rol de la colectividad en la creación literaria? y (4) la construcción individual de persona escritora-privada de libertad: ¿cómo es el tránsito vivencial en el que está una persona escritora y privada de libertad?

\subsection{Relación objetivos planteados-resultados obtenidos}

La relación entre objetivos y resultados que acá se pretende exponer, es de carácter cualitativo. Por tanto, sus indicadores están asociados a la observación 
participante de los facilitadores dentro del proceso, así como los testimonios de las personas participantes y los productos obtenidos. Además, es un espacio que permite contraponer el papel con la realidad, es decir, lo que se tenía planificado con lo que realmente sucedió.

Así entonces, el objetivo principal que era rescatar y promulgar el patrimonio artístico y cultural de las personas privadas de libertad en el CAI Sandoval de Limón, es cumplido a cabalidad en tanto:

- Se realizan todas las sesiones planificadas de manera ininterrumpida.

- $\quad$ Existe anuencia por parte de los participantes a ser parte del proceso.

- Se rescata el patrimonio artístico y cultural de los participantes, al registrarse en un libro llamado Cementerio de los Vivos (2016).

- Se promulga el patrimonio artístico y cultural de los participantes al exponer su libro en cuatro recitales, más de cinco medios de comunicación y todas las bibliotecas públicas del país.

- Se logra la constitución de un espacio llamado Taller Literario Reencuentro con los Vivos, instalado en el CAI Sandoval de Limón y con la participación de los 13 autores.

Para efectuar lo anterior se encontraron algunos obstáculos que dificultaron el cumplimiento del objetivo general; uno de carácter espacial, otro cultural y otro estructural. El primero de ellos es la lejanía entre el centro penitenciario y las casas de habitación de las personas facilitadoras. El otro obstáculo tiene su asidero en un problema cultural relacionado con el hábito de la lectura. A pesar de que se les facilitó una antología con más de 100 obras literarias y se les asignó tareas de lectura, la respuesta fue escasa o nula. El tercer obstáculo está relacionado con la divulgación del libro. Ya que solo medios de alcance moderado y universitarios le dieron difusión a los comunicados de prensa.

\subsection{La facilitación}

El recinto universitario donde se llevó a cabo el proyecto: Liberando ecos, fue en la Unidad de Educación del centro penitenciario. Este sitio es utilizado por el régimen de instituciones dedicadas a brindar posibilidades de educación a la población privada de libertad en el Centro de Atención Integral. El proyecto fue ubicado como parte de los cursos de extensión cultural de la Universidad Estatal a Distancia. 
Por tanto, lo que podría denominarse la acción pedagógica (Gil, 2010), se sitúa en un escenario institucionalizado (UNED-CAI Sandoval), pero su sustrato pedagógico está asociado al tipo de educación no formal. Esta relación no es incompatible, de hecho, procesos de enseñanza a distancia, universidades, o campus virtuales, y en general, las denominadas formas flexibles de educación, mantienen un nexo visible con alguna institución de la educación formal, ya sea administrativa o económica y hasta políticamente. La distinción entre estos dos tipos de es básicamente jurídica, pues a pesar de que se dote a la educación no formal de una exclusividad en sus características pedagógicas, más bien pretende dar cuenta de los fenómenos educativos y de sus formas no convencionales, "no surge en oposición a, sino por la perentoria necesidad de que la labor de la escuela se desarrolle fuera de ella, en otros ámbitos sociales o cívicos, pues la necesidad de la educación se ve, a partir de los años setenta, como una necesidad plural y permanente." (Colom, 2005, p. 15).

Los procesos llevados a cabo en el proyecto tienen una finalidad explicita relacionada con el aprendizaje, mediante nuevas estrategias pedagógicas, distintas o al menos independientes de la educación formal. El hecho de rescatar y promulgar el patrimonio artístico y cultural de las personas privadas de libertad en el recinto penitenciario Sandoval de Limón, tiene su origen en aprender conjuntamente las numerosas formas de expresión escrita y artística inmersas en la creación poética, con el fin último de brindarles la oportunidad de ser publicados como portadores de una voz creativa.

Las personas privadas de libertad son como comunidad cultural, una de las voces más silenciadas en la sociedad costarricense, esto debido a la marginalización que experimentan al ser juzgados socialmente por la comisión de algún delito, sin que una vez egresados de la prisión, la sociedad brinde oportunidades reivindicativas para estas personas. Al salir de los centros penitenciarios cargan consigo un estigma social que les limita sus posibilidades de desarrollo y al tener un documento legal (hoja de delincuencia) manchado, se limitan aún más nuevas posibilidades de empleo, lo cual pareciera obligarles nuevamente a una vida criminal. Aunado a esto las malas condiciones, el abandono y en general el colapso del sistema penitenciario costarricense hace más difícil una readaptación social eficaz.

Otro aspecto, donde se sitúa la acción pedagógica es la población con la cual se trabaja. Cómo se mencionaba anteriormente, los privados de libertad se encuentran en una posición de marginalización y de violación a gran cantidad de sus derechos humanos, principalmente en lo que se refiere a las problemáticas provenientes de la prisión preventiva y hacinamiento carcelario. (OEA, 2016) (Defensoría de los Habitantes de la República de Costa Rica, 2010). El CAI Sandoval, es un reflejo 
de esta realidad. Además, poseen una historia de vida relacionada en muchos casos, con experiencias de violencia física y emocional, también de reflexiones asociadas con el cautiverio. (Trilla, 1993) Por otro lado, la privación de libertad provoca una desvalorización de la acción de la persona, que le va minando actitudes y aptitudes de carácter social. (Gil, 2010).

Esto produce que la acción pedagógica en centros penales tenga distinciones específicas a tomar en cuenta. Una de ellas es que las personas facilitadoras del proyecto desde su perspectiva como educadores sociales se posicionen a partir de sus ámbitos delimitados, por los objetivos del proyecto, es decir, contribuir "específicamente a mejorar la dimensión comunitaria y social de los aprendizajes de los internos" (Gil, 2016, p. 57) y no cumplan el rol de otros profesionales de psicología u orientación.

Lo anterior es de suma importancia, puesto que la gestión cultural en centros penitenciarios, como en cualquier otro lugar, despierta en las personas participantes emociones con las cuales, quienes facilitan, tendrán que lidiar y lograr canalizar hacia los objetivos propios del proyecto que se está ejecutando, siempre a través de herramientas de carácter participativo. En el caso de los centros penitenciarios, es una gestión cultural en los márgenes de la sociedad y debe construir la acción pedagógica de sus contenidos, contemplando la reclusión. Dicho de otra forma, quien participa facilitando un proyecto de extensión cultural debe habitar la cárcel como cualquier otro, debe aprender a lidiar con el cautiverio.

Así mismo, debe existir un imperativo dentro de los objetivos de un proyecto pedagógico en prisión que tenga origen en defender el derecho de los privados de libertad, en adquirir la condición de agente de sí mismo, a través de la actividad y la participación, promoviendo el principio de actividad de la persona privada de libertad. Cómo menciona Gil "la pasividad, la quietud, la inactividad, el estar tirado en el patio, aunque sea su derecho, despersonaliza a los sujetos convirtiéndoles en voluntades enajenadas, flojas, susceptibles de manipulación” (Gil, 2016, p. 60).

Sobre el proceso de "readaptación social" en los centros penitenciarios, Ana Evangelina Talavera afirma también que "la reflexión del sujeto sobre su propia vida dentro de la prisión es necesaria, sin embargo la institución penitenciaria sólo es vista como institución de corrección de los sujetos" (Talavera, 2010, p. 25). También, es posible percibir visiones sobre la gestión cultural en centros penitenciarios como eventos de mero entretenimiento o distracción (Mapelli, 2006). Es por tanto que un proceso reivindicativo, y reflexivo no puede venir si no es por una autorreflexión y un autoconocimiento de los participantes. En el 
caso del proyecto, la construcción de procesos creativos y pedagógicos asociados a la poesía, tienen este objetivo ulterior.

Por tanto, la presencia de una metodología lúdica que cumpla con diferentes funciones se vuelve una acción pedagógica fundamental. La utilización de herramientas prácticas sirve en el desarrollo profesional de los participantes, una vez egresados del centro penitenciario, tales como habilidades de expresión oral y escrita, capacidad de síntesis y análisis, y trabajo en equipo.

Este espacio de creación y reflexión, permite también, que, a través del aprender desde su propia dignificación, se tenga la capacidad para afrontar la consecución de un objetivo común, el cual en este caso, fue la publicación de un libro colectivo, en donde se publicaron las subjetividades de los participantes. La consecución de esto se dio a través de un proceso en el que se reconocen como sujetos artísticos con un saber particular y valido. Proceso que además, les dote de herramientas para la construcción de una sana autoestima y confianza.

\subsection{El grupo como plataforma para escribir}

El Taller Literario Reencuentro con Los Vivos es el resultado de la concepción intracolectiva de la identidad que se logra construir durante el proceso. No es una coincidencia que el libro y el espacio tengan un vínculo nominal; corresponde a la toma de conciencia o introyección sobre el proceso. Según la observación realizada, esto se debe en gran parte al tránsito grupal hacia la educación no formal, tomando como punto de partida la educación formal.

El taller como espacio donde se editan grupalmente los textos de cada participante, fue un momento de construcción literaria, donde se contemplaron reglas básicas de edición como el respeto al texto del otro, la formulación de argumentos en posición de mejorar el texto del otro, también dar con la idea de que se construye un libro colectivo, en tanto, los textos que estén ahí tienen que ser los mejores y se debe ayudar a los compañeros a que den su mejor esfuerzo. Esta construcción de una otredad literaria es una muestra de esa realidad del cuerpo-dignificante como concepto operacionalizador de este proceso.

Esto último, también fue posible observarlo en los tres recitales posteriores a la publicación del libro. El acto colectivo y performático que significó la lectura de personas privadas de su libertad en un espacio abierto es situar sus cuerpos-dignificantes, a la vista de todas las personas presentes no privadas de libertad. Sobre todo, es importante visibilizar el papel del familiar que realiza la visita penitenciaria en un lugar totalmente diferente al que lo hace habitualmente. Este reencuentro 
en libertad, también sitúa al familiar como cuerpo-dignificante y demuestra que proyectos de este tipo generan externalidades positivas en las poblaciones en prisionalización secundaria (Caldera, 2014).

\subsection{La construcción individual de persona escritora-privada de libertad}

Este ámbito de la observación vivencial es el más limitado de los facilitadores para observar, pues significaría un trabajo más extenso de observación individual y sobre todo, la posibilidad de un solo trabajo en específico, inclusive de un programa de investigación, sobre esta temática. Fue posible establecer un análisis a partir de entrevistas que se realizaron a tres participantes del proyecto y que fueron grabadas para darle divulgación a los productos confeccionados (Vertedero Satélite, 2016). También, podría realizarse un análisis de discurso sobre las obras literarias publicadas, pero se propone que la explicación de los textos debe reservarse, en este caso, a los autores.

Lo primero que se puede resaltar de este tránsito entre persona escritora y privación de libertad es la posibilidad de un nuevo plan de vida. Según los participantes, el ser una persona escritora engloba al menos tres beneficios (1) divulgar sus realidades hacia el afuera del centro penal, (2) comprender que la literatura es una expresión espontánea, (3) ser un actor sensibilizante sobre los derechos humanos de las personas privadas de libertad.

A partir de estos testimonios, el tránsito que acá se describe demuestra un cuerpo-dignificante que interseccionaliza su condición de escritor y también de ser una persona privada de libertad. El uso útil de ambos roles para la construcción de literatura, pero también para resignificar el concepto de persona privada de libertad es un efecto propio de la introyección, por parte de los participantes de la metodología utilizada durante el proceso.

En la entrevista, la pregunta más importante fue ¿qué se siente ser escritor? Esto permitió situar la conversación en su rol de escritores, solamente. Aun así, la lectura por parte de los participantes de esta pregunta fue situarse como escritores privados de libertad.

\section{El punto de partida, lo teórico que nos precede}

\subsection{Una metodología desde las epistemologías del Sur}

Se ha considerado pertinente para el análisis de la experiencia realizada en el CAI Limón, el establecer los puntos de encuentro hallados con nuevas apreciaciones de la ciencia y el conocimiento, en este sentido, resulta importante 
para una experiencia del presente tipo, el caracterizarse como un proyecto que cuestiona la racionalidad moderna tradicional y se posiciona como una propuesta crítica/alternativa.

Esta intención de considerar en la experiencia aquello que se entrelaza a epistemologías críticas, radica en la necesidad de establecer una diferenciación del modelo global de Racionalidad Científica Imperante. Respecto a esta tendencia conservadora, el autor Boaventura de Sousa Santos menciona: "Siendo un modelo global, la nueva racionalidad científica es también un modelo totalitario, en la medida en que niega el carácter racional a todas las formas de conocimiento que se pautaran por sus principios epistemológicos y por sus reglas metodológicas." (De Sousa Santos, 2009, p. 21).

Según los cuestionamientos, en la noción de la modernidad occidental, el elemento de la razón metonímica, ha estructurado el conocimiento en dicotomías excluyentes y jerarquizadas que no se contemplan de manera particular, sino a partir de un razonamiento binario, el cual fue uno de los pilares de la homogeneización del conocimiento, de manera que todos aquellos saberes ajenos a la racionalidad metonímica debían ser sometidos o alienados.

Al considerar lo anterior, el presente trabajo comprende el carácter de reivindicación de los saberes marginados, y las formas de conocimiento alternativas, punto trascendental con el cual se llevó a cabo la experiencia con los 13 autores del libro que resultó como producto del proyecto denominado: Cementerio de los Vivos.

Precisamente, para evidenciar los elementos del proyecto que contemplaron las epistemologías críticas del sur, se procederá a establecer una diferenciación de las variables que De Sousa Santos (2009), considera como: "Las cinco lógicas de producción de la no existencia”, dicha diferenciación se establecerá en cada una de las ecologías propuestas por De Sousa para la confrontación del conocimiento hegemónico, con las respectivas particularidades de la propuesta del colectivo, para la reivindicación de la dignidad, ejecutadas en el Proyecto Liberando Ecos y plasmadas en la constitución del libro mencionado como su producto.

La primera lógica es la denominada "monocultura del saber y del rigor del saber", la cual establece que el saber de la ciencia moderna y la alta cultura son los únicos que se instauran como válidos en la legitimación y la producción de arte y conocimiento, a partir de los cánones existentes. En la experiencia del proyecto con los autores privados de libertad, se llevó a cabo una propuesta colectiva y contrahegemónica que estableció una diferenciación en ese sentido, pues al llevar el arte, las formas de expreción corporales, la expresión oral-escrita y otras diversas 
herramientas de expresión a las personas privadas de libertad, estas pudieron comunicar y plasmar sus saberes y necesidades a partir de la poesía y la corporalidad.

La segunda lógica es la "monocultura del tiempo lineal", la cual establece que el razonamiento tradicional moderno ha estipulado que el carácter rectilíneo del tiempo es la única forma de asimilar el mismo en términos de vida, historia y sociabilidad. Al considerar dicha visión, se estableció una diferencia que comprendió las diversas temporalidades de los actores sociales, comunidades y naturaleza, respetando que los tiempos de vida y principalmente, las experiencias, pueden desarrollarse y compartirse independientemente, de las construcciones y prejuicios de la sociedad y de la "monocultura del tiempo lineal".

En este sentido, el trabajo que el colectivo ha desempeñado con personas privadas de libertad en centros penales, ha significado un desaprender de la temporalidad dentro y fuera del centro penal, así como también, de sus experiencias y sus vidas, según las penas carcelarias, elementos que evidencian la relatividad de dicho elemento temporal.

La tercera lógica gira en torno a la clasificación social, dentro de ella De Sousa Santos considera que ha sido instituida una naturalización de las diferencias, lo cual a su vez permite que se establezca una categorización de los individuos según su clase, de manera que este raciocinio lleva a la inexistencia de algunas personas o a la supremacía de otras. Para confrontar esta lógica, el autor propone una ecología de los reconocimientos en lo concreto, en el presente trabajo, se propuso la visibilización y la dignificación a partir de la autopercepción de los autores como escritores.

La cuarta lógica es la denominada de la escala dominante, a partir de ella se expone que la contemporaneidad está regida por la hegemonía de las escalas de lo global y lo universal, estas legitiman conceptos universales que a partir de una abstracción imponen un orden de mundo, entre ellos pueden encontrarse por ejemplo: “... el comercio libre, la democracia, la primacía del derecho, el individualismo y los derechos humanos tradicionales." (De Sousa Santos, 2009, p. 121).

Para la experiencia abordada en el presente artículo, se dio una ruptura de la Lógica de escala dominante, a partir del sustento teórico de la ecología de las transescalas, de manera que se generó una revaloración de las escalas locales y particulares, trabajando directamente con las poblaciones que se encuentran dentro de ellas. De modo que la dignificación de su condición, su vulnerabilidad y sus luchas, se diera desde una revaloración a partir de la cultura local, en este caso la cultura del Caribe costarricense. 
La última lógica de no existencia se adscribe a la productivista y se establece principalmente en la economización de la sociedad y el carácter productivista que el capitalismo y el neoliberalismo pregonan en el nivel global. Según esta lógica, el posicionarse dentro de las dinámicas de consumo y producción es una labor innegable de toda sociedad e individuo, al dejar de lado cualquier razonamiento o conocimiento que se aparte de la racionalidad capitalista.

Ante esta determinada lógica y tomando en cuenta la ecología de las productividades, la experiencia propuso cuando fue necesario, el revalorar las diversas formas de producción, y los muchos estilos de vida locales que se aparten de dicho razonamiento.

Otro elemento importante en la experiencia del proyecto el cual es abordado desde, las epistemologías del sur, es el concepto del pensamiento abismal, a partir del cual se establecen distinciones entre lo que De Sousa denomina: personas visibles e invisibles, constituidos a su vez en paralelos opuestos, de un lado de la línea o de otro lado de la línea.

La importancia de esta línea que se plasma con el pensamiento abismal, es que permite considerar de una forma gráfica las distinciones que se generan en el nivel social y humano, según el conocimiento moderno, De Sousa Santos lo denomina una "distinción universal entre lo verdadero y lo falso" (De Sousa Santos , 2009, p. 162), a partir de lo cual lo falso se manifiesta como los saberes no académicos o no modernos, tales como los conocimientos campesinos o indígenas, mientras que lo verdadero se establece como todo aquel conocimiento resguardado en una disciplina moderna.

El uso de este concepto en la exposición de la presente metodología y la experiencia del proyecto desarrollado, se justifica en el planteamiento que el colectivo establece del arte y de las metodologías lúdicas, como herramientas de dignificación de todo aquel conocimiento y todos aquellos individuos que se encuentran al otro lado del pensamiento abismal. Para lo cual, el proyecto pretendió afirmar que todo individuo (en este caso personas privadas de libertad), tiene saberes válidos independientemente de su legitimidad, dentro de la modernidad, y que además puede contar con diversas formas de manifestarlo y visibilizarlo para a su vez legitimarlo, de manera que todas aquellas "experiencias desechadas" (De Sousa Santos , 2009, p. 163), por la modernidad, por la institucionalidad o por los prejuicios sociales, se reivindican y se manifiestan con su dignidad plena. 


\subsection{Sobre el cuerpo como espacio de conocimiento. Crítica a los pensamientos que plantea el arte, únicamente como herramienta didáctica}

Desde la multidisciplinariedad, se ha planteado la posibilidad de ver en las artes metodologías lúdicas, una manera de acompañamiento en los procesos de aprendizaje, así se plantean términos no formales (dentro y fuera de los espacios institucionales) que proponen la posibilidad de un acompañamiento desde las artes a los métodos lógico racionales de los conocimientos, de manera que se establecen innovaciones didácticas, en donde el estudio y el tratamiento de conflictos sociales se han acompañado de expresiones artísticas para la asimilación, la producción y la expresión de los conocimientos.

Estas iniciativas resultan fundamentales en la propiciación de espacios alternativos e integrales, generadores de un mejor y dignificado estilo de vida. Sin embargo, se considera fundamental reconocer como saberes igualmente válidos a los racionales, aquellos producidos en colectivo a través de la apropiación y el autoconocimiento del cuerpo, mediante la exploración creativa de las diferentes manifestaciones artísticas. Así, se plantea que las herramientas brindadas por las artes, no sean solo medios de acompañamiento para un fin específico sino, como parte del entramado complejo del quehacer educativo y social. En sí mismos, los procesos exploratorios y creativos son creadores de sentido y conocimiento, sin que estos deban necesariamente pasar por los sistemas racionales.

Así mismo, se plantea explorar las diferentes posibilidades del lenguaje, tanto corporal como escrito y oral, a través de lo metafórico, de las imágenes en la poesía, la expresión de este a través del cuerpo, el movimiento auténtico, el performance y en fin, la posibilidad espontánea de la comunicación por medio de todos los sentidos. De manera, que se extienden las fronteras de la comunicación, lo cual es un hecho contra hegemónico, en una cultura capitalista globalizada, donde se da privilegio al sentido de la vista y el oído en un segundo grado, en detrimento de las posibilidades cognoscitivas del resto del cuerpo. De manera que se plantea la corporalidad no como objeto de pertenencia de un sujeto abstracto, sino como la persona misma, con un sinfín de posibilidades de creación, las cuales se potenciarán en contacto con otros cuerpos-individuos. Esta concepción de lo corpóreo es la que el colectivo entiende como base para la comprensión y la manifestación física de un cuerpo-dignificante.

De tal manera, se cuestionan en el nivel epistemológico y ontológico, la lógica de la modernidad occidental que divide las disciplinas artísticas (el arte liberal), y que limita a las artes como conocimientos secundarios en virtud del privilegio epistemológico de lo racional. Siguiendo a De Sousa Santos se señala que: "Es 
necesario, proponer un modelo diferente de racionalidad. Sin una crítica de dicho modelo de racionalidad occidental dominante al menos desde hace dos siglos, todas las propuestas presentadas por el nuevo análisis social por más alternativas que se juzguen tenderán a reproducir el mismo efecto de ocultación y descrédito". (De Sousa Santos, 2009, p. 99, 100).

Esta propuesta estética y metodológica se piensa en función de la generación práctica de estilos de vida alternativos, dignos e integrales. De tal manera que se concuerda con la idea de Edgar Morin en "La cabeza bien puesta", pues existe una necesidad de espacios (Morin se refiere específicamente, a los espacios de educación formal en las escuelas) que generen conocimiento de "la cualidad poética de la vida y, correlativamente de la emoción estética y del asombro". (Morin, 2002, p. 50)

Se propone el cuerpo-dignificante como un sujeto histórico que carga en sí mismo en el nivel discursivo y estético, un sin número de símbolos y por tanto, cargas sociales en la manifestación de su ser físico. De manera que un cuerpo negro o indígena no significa a nivel social de igual manera que uno blanco; uno femenino no crea desde los mismos lugares, ni ejerce iguales poderes que los cuerpos masculinos; un cuerpo joven no posee los mismos privilegios que uno adulto y un cuerpo empobrecido no posee iguales facultades que uno con ventajas económicas.

Por dignidad, se comprende por lo tanto, el proceso progresivo en el que las personas ostentan una vida con las condiciones materiales, emocionales, sociales y espirituales que les permiten un desarrollo personal a plenitud. En este sentido, la dignidad es un proceso en construcción que desde una visión crítica de los derechos humanos involucra bienes materiales tales como: el acceso a una vida y ambiente sanos, así como a bienes inmateriales, como lo son la libertad, la paz, la expresión y la creatividad. La dignidad por lo tanto, es construida en colectivo, y no es, solamente, un estado subjetivo e individual, esta crece en la medida en que se entiende que el bienestar de las otras personas es parte de mi propio bienestar, de manera que la lucha por la dignidad es multifactorial y multiescala.

Al considerar los análisis interseccionales brindados por los feminismos poscoloniales, se interpreta que un cuerpo-dignificante es en sí mismo un espacio de creación y creatividad, que se ve tanto limitado como vetado por sus características socioeconómicas, étnicas, fenotípicas, de orientación sexual y de género. Por ello, la metodología propone encuentros artísticos y colectivos que en contra de un juzgamiento hegemónico de las personas, sea la diversidad corporal la mayor posibilidad de creación y creatividad. 
Siguiendo a De Sousa Santos se trabaja a partir de una sociología de las emergencias en donde, el compromiso artístico y social, sea el de visibilizar en colectivo todo aquello que esté al alcance de las posibilidades del ser, no desde lo que se podría llamar una acción subversiva de la filosofía o el arte moderna en la que el filósofo o el artista representa la voz del pueblo, sino más bien un compromiso que conlleve construir nuevas formas de hacer y crear en colectivo.

De manera que se comprende la sociología de las emergencias como aquella que "consiste en sustituir el vacío del futuro, según el tiempo lineal (un vacío que tanto es todo como es nada), por un futuro de posibilidades plurales y concretas, simultáneamente utópicas y realistas, que se van construyendo en el presente a partir de las actividades de cuidado”. (De Sousa Santos, 2009, p. 127).

Es por tanto, que más allá de inconmensurabilidad de los conocimientos diferenciados por la lógica de la modernidad, se plantea una complejidad de saberes que apunte no al conocimiento absoluto, sino a la posibilidad constante de una creación de conocimiento que haga uso de los conceptos y las categorías para plantear vías de comunicación y traducción entre los saberes. Esto en virtud de una constante revisión del apropiamiento del espacio por los participantes, que a su vez dé lugar al cuerpo-dignificante como fuente primaria de hacer y conocer, dando principalmente, un espacio al quehacer grupal y el apropiamiento subjetivo de la creación artística.

Esto es lo que se llamaría una metodología de la intersubjetividad, transdisciplinariedad y traducción paradigmática de los conocimientos. Metodología propuesta como alternativa para lograr el fin último de la expresión y la visibilización de las injusticias, el apropiamiento crítico de los derechos humanos y la posibilidad de un futuro plural y concreto. El libro Cementerio de los vivos (producto final del proyecto: Liberando ecos), responde a esta metodología, en tanto es el producto sintetizado de un esfuerzo colectivo que comparte los conocimientos intersubjetivos, transdisciplinarios, y paradigmáticos de 17 sujetos a través de una antología poética.

\subsection{Sobre los procesos de aprendizaje creativo y la salud, entendidos desde la perspectiva} de la espontaneidad sociométrica

De manera tradicional o popular la espontaneidad puede ser vista como un impulso o una manifestación instintiva de las ideas y las acciones, una conducta sin freno, y no atendiéndose a norma alguna. Esta herencia conceptual de la doctrina secular de Rousseau y el cientificismo europeo, describe la espontaneidad al omitir los elementos creadores implicados en ella como instancia de la existencia humana, principios que implican un replanteamiento de las dicotomías de lo racional contra 
lo irracional, del orden del cosmos olímpico contra el caos mundano, de la mente en diferenciación del cuerpo y de la salud frente a la enfermedad.

El rescate de esos principios omitidos y el replanteamiento de esas y otras dicotomías, es realizado en el abordaje de la teoría y la metodología de la sociometría, iniciada por Jacob Levy Moreno en 1934.

La espontaneidad es entonces entendida por este abordaje como el núcleo de los procesos de salud-enfermedad en el ser humano, y por lo tanto, también como el de la Teoría sociométrica en sí. La cual es vista como aquello que en el aquí y el ahora impulsa a la persona hacia contestaciones adecuadas en situaciones nuevas y a respuestas nuevas en situaciones conocidas. Según como lo describe la sociometría, la espontaneidad le permite a la persona encaminarse a la realización de acciones que transformen su realidad personal y social, sin enajenarse de ellas, a la vez que rompe con esquemas de comportamiento propios de una actitud mecánica y estereotipada generados por las conservas o las hegemonías en los discursos y la cultura, las cuales tenderían a su vez a ahogar el potencial creador de la persona, los grupos y la sociedad misma, y consecuentemente a enfermarles.

La espontaneidad en la sociometría supone dos dimensiones, una filosófica y otra psicológica, en profundidad filosófica la espontaneidad se opone a la noción física de la energía en estado de conservación, mientras en la psicológica describe la espontaneidad en tanto, desarrolla en la persona un estado de perpetua originalidad, y a la vez de adecuación personal y existencial, ante las circunstancias vitales. En resumen, supone la constante creatividad en el mundo, la realidad, y el inmanente potencial creador de la persona, quien se expresa principalmente, a través de sus acciones en el momento en que logra canalizarla adecuadamente.

Con base en la aplicación práctica de este concepto en la experiencia llevada a cabo, se vuelve ineludible rescatar lo también abordado en el apartado anterior; una (des)comprensión del aprendizaje, al supera la única noción de acumulación de contenido técnico, moral e intelectual, y donde entonces se permite integrar el entendimiento del proceso de enseñanza-aprendizaje en tanto disposición vital o propia de la vida humana en su totalidad.

Los sucesos que formaron parte de la experiencia vivida con los autores del libro Cementerio de los vivos (2016), durante el desarrollo del proyecto que fundamenta esta metodología, integraron un proceso de aprendizaje horizontal constituido de herramientas y prácticas de escritura poético-literaria, pero también de momentos y acciones que evidenciaron la creación de un espacio de autodignificación de cada sujeto, de recursividad intersubjetiva ante acontecimientos biográficos sucedidos en 
el pasado o el presente de cada participante, de generación de autonomía creativa en oposición a perfeccionismos estéticos o intelectuales que comúnmente supone la práctica hegemónica del sujeto que escribe, y de proyección personal en tanto personas creadoras y poseedoras de una práctica vital poética.

Sobre estos resultados se desarrollará un apartado siguiente, sin embargo, ante esto resulta necesario incorporar a la comprensión de la experiencia y lo que fundamenta la metodología, que ninguna de las personas participantes del proyecto, exceptuando claro al equipo facilitador, se concebían así mismos, como escritores previo a lo sucedido, por lo tanto, la invitación realizada consistió también, en construir en colectividad una experiencia de aprendizaje multidimensional de la escritura, basada en la improvisación, sobre este tipo de procesos, Garrido (1978) los describe de la siguiente manera:

Se analiza el sujeto y se ve dónde radica su defecto, y a partir de aquí se le obliga a improvisar estados psíquicos o circunstancias externas que intentan corregirlo. No se trata de aprender un hecho o un acto concreto, sino más bien una actitud que habilite al sujeto para solventar adecuadamente las diversas circunstancias que se le pueden presentar en la vida real, en el desempeño de su oficio. (Garrido, 1978, p. 164)

Si bien el autor describe el proceso en tanto sugestión del sujeto a un estado de improvisación ante lo desconocido, y a diferencia, la experiencia referenciada partió en favor de una invitación a la participación voluntaria y libre, esta descripción nos permite entonces dar cuenta de la implicancia de la improvisación como proceso psicosocial de aprendizaje, donde la práctica compartida en un ambiente que propicia la espontaneidad, genera una experiencia suficiente para incorporar como recursos de la subjetividad: comportamientos, principios, resonancias y relatos biográficos que pueden ser agregados a nuestra actitud cuando la vida misma lo requiera.

Los resultados enunciados así mismo, subrayan experiencias que implican un proceso de transformación positiva sobre determinadas condiciones psicosociales de los participantes del proyecto, esto debe leerse desde la espontaneidad, como condición de salud o salutogénesis en las personas participantes, en la medida en que las transformaciones descritas apuntan al aporte hacia una reconstitución gradual y grupal de condiciones de (auto)dignificación psicosocial de cada participante, frente a su realidad inmediata de privación de sus libertades individuales y grupales.

Por lo tanto, se incorpora de esta forma en la metodología una lectura de la salud basada en las capacidades creadoras de las personas como catalizadores de autodignificación, salud psicosocial y de recursividad subjetividad ante las circunstancias 
y los contextos vitales que se enfrentan. Esta lectura, es desarrollada por la teoría sociométrica, la cual describe la salud de la espontaneidad en la medida en que deviene en el sujeto condiciones psicosociales de flexibilidad, poder y creatividad, de forma tal que la persona ha de lograr mantener aún frente a las conservas o hegemonías culturales que le oprimen, (1) una flexibilidad de su conducta a través del dominio recursivo de estas (evocando a la actitud de quien inició esas conservas), (2) una sensación de poder subjetivo frente al dominio que las hegemonías le imponen, y (3) la re-creación de su propia personalidad frente a lo socialmente establecido como legítimo, en oposición a la estereotipación de sus propias conductas y la expectación social de determinados patrones sociales de comportamiento. (Garrido, 1978).

\section{Materiales y métodos para una metodología crítica, para la construcción de una dignidad en resistencia}

Por lo tanto, se describen los principales postulados que apoyaron tanto el proyecto que da génesis a esta metodología. Estos corresponden a dos de los principales postulados desarrollados desde la sociometría (sociodrama y psicodrama), y el abordaje construido por el Circulo Literario Vertedero Satélite como el Taller de aprendizaje no formal y edición de la escritura poética.

\subsection{Psicodrama}

Para Reyes (2006), el psicodrama es un paradigma integrado por una teoría, un método y una serie de técnicas. Esto comprende nuevamente, según la misma autora, al ser humano como uno eminentemente social, por lo que desarrolla su teoría y metodología con base en las relaciones interpersonales y la intersubjetividad. Lo cual le permite al método psicodramático privilegiar el encuentro, las posibilidades del vínculo y la espontaneidad.

Reyes además señala que el psicodrama realiza su trabajo a través de momentos claves, Moreno, citado por la misma autora, los específica como: caldeamiento, la representación dramática o acción y el Sharing.

\subsection{Sociodrama}

El sociodrama, según (Howie, 2014), puede ser utilizado en grupos pequeños condicionados por temáticas específicas, hasta conjuntos de mucha mayor amplitud y complejidad temática; su devenir parte de propósitos de indagación y exploración de situaciones micro- y macrosociales, o con la intención de resolver conflictos o enseñar al respecto de problemáticas sociales determinadas. El sociodrama, 
aunque parte de los mismos supuestos y herramientas teórico-metodológicas que el psicodrama, se centra en la transformación específica de roles y temas sociales, sacrificando el enfoque respectivo de la terapia psicodramática de los trastornos emocionales y psicopatológicos.

\subsection{Taller de aprendizaje no formal y edición de la escritura poética}

Este taller de aprendizaje no formal y edición de la escritura poética se plantea como una metodología de desarrollo empírico para la edición participativa de poemas, por escritores que producen creativamente este tipo de literatura (poesía). La cual surge como una propuesta de desarrollo propia que toma como base la sistematización de saberes, técnicas y protocolos de edición desarrollados, por talleres de poesía en la provincia herediana, así como las experiencias prácticas de los integrantes del Circulo Literario Vertedero Satélite, en el desarrollo de una implementación propia de dichos conocimientos.

El cual a la vez se fundamenta en la práctica de la Educación No Formal, entendida como toda actividad educativa organizada y sistemática, realizada fuera del ámbito oficial, que apela a facilitar ciertos aprendizajes particulares. Como su nombre lo indica, se define desde la negativa y la oposición a la educación formal, aquella reconocida e institucionalizada, cronológicamente graduada y jerárquicamente estructurada. Y que además, se caracteriza por tener una mayor flexibilidad que el sistema educativo formal, promover prácticas voluntarias, generar mayor variedad temática, implementarse bajo una heterogeneidad del grupo participante; y no pretende homogeneizar el aprendizaje, no se estructura en niveles jerárquico, aspira a logros independientes, no culmina con la entrega de acreditaciones, aunque suele reconocerse, y donde los educadores no siempre son profesionales.

El método consiste en un proceso de edición colectiva del texto producido creativamente por el autor, a través del auscultado rítmico, sintáctico, semántico y pragmático del poema en sus dos dimensiones de expresión o comunicación: oralidad y textualidad. En su expresión oral, el texto es analizado con base a la performática, estética rítmica y su musicalidad, en su lectura del idioma castellano. Para el análisis de esta dimensión, se procede a través de la técnica del foro de discusión, con la cual el trabajo es auscultado a partir de la apreciación de un grupo participante que lee y escucha el poema, primero a voz del autor y posteriormente, leído por una segunda persona, que luego expresan sus opiniones o apreciaciones en esta dimensión.

En su expresión textual, el trabajo es analizado con base en su composición sintáctica, semántica, pragmática y literaria, tomando como fuente el producto literario 
del autor plasmado sobre una hoja de papel. Para el análisis de esta dimensión, se realiza una lectura y revisión colectiva de las distintas semiosis identificadas, así como de otros elementos representativos de estilos literarios analógicos al poema, la revisión entonces finaliza con una retroalimentación al escritor de los resultados de este auscultado individual y colectivo del escrito a través del foro de discusión. Las observaciones recibidas tácitamente por el autor son entonces implementadas o no para futuras modificaciones del poema, como producto creativo, a través de una edición personal de su trabajo.

Por tanto, la presencia de una metodología de creación y edición de los poemas que cumpliera con diferentes funciones se vuelve un hecho pedagógico fundamental. La utilización de estas herramientas prácticas sirve en el desarrollo profesional de los participantes del proceso pedagógico, en términos del desarrollo de sus habilidades de expresión oral y escrita, capacidad de síntesis y análisis, y de trabajo en equipo.

\section{Los tres principios contrahegemónico, colectivo y performático}

\subsection{Lo contrahegemónico}

Por contrahegemónico se entienden todas aquellas posibilidades creativas de los sujetos de establecer imaginarios dinámicos, alternativos, intersubjetivos y complejos creados desde el lugar del no ser de la línea abismal, y que por, tanto se posicionan antagónicamente frente a los discursos hegemónicos de la cultura moderna. Para los fines concretos, lo contrahegemónico se opone al discurso oficial de los derechos humanos y del arte liberal.

\subsubsection{Dignificación de las vidas, derechos humanos y las posibilidades del arte literario}

Desde un enfoque crítico de los derechos humanos, el planteamiento se hace fundamental en virtud de la dignificación de las vidas a través de la apropiación de todas las áreas, en este caso el espacio artístico por medio de la literatura. La dignidad humana, en un sistema de derechos normado por los preceptos morales y biopolíticos de la modernidad patriarcal capitalista y racializada, está sujeta a las condiciones materiales y culturales de los individuos. De tal manera que se pueden evidenciar clases de seres humanos, no solo desde la categoría de lo material, sino al ampliar el concepto a parámetros culturales, étnicos y sociopolíticos, por tanto, existen dignidades diferenciadas de acuerdo a las posibilidades adquisitivas de los individuos, su condición de género, su origen étnico y cultural, y su contexto sociopolítico. Esta diferenciación de la dignidad entre seres humanos si bien es desdibujada en documentos, convenciones y tratados 
de derechos humanos, en la cotidianidad se hace evidente al limitar los derechos de las personas no privilegiadas.

Ante la normativa formal de los Derechos Humanos, se pretenden acciones participativas y resistentes, que impulsen desde la autonomía, la apropiación de derechos y la dignificación autogestionada de las vidas, ya sea como procesos formales o al margen de la normatividad de los Derechos Humanos. Siguiendo a Herrera Flores, se presenta el apropiamiento de los espacios literarios como contra propuesta, como el sí, al cual subyace el reclamo por las injusticias y desigualdades sociales.

Las personas validan sus vidas, quehaceres y orígenes socioculturales a través de un espacio lúdico, participativo y abierto en donde las historias son igualmente válidas. Ellas, se convierten en las protagonistas de sus propios poemas, cuentos y relatos, generando una validación de sus sentires, dando paso además a la exploración creativa, el asombro y la espontaneidad constante, producto de los ejercicios creativos. La autonomía y la validación de derechos a la vida, a la dignidad, a la igualdad, a la libertad, a la diversidad, a la opinión y expresión, no solo se hacen manifiesto en los productos de creación colectiva, sino que también, se recrean y construyen desde las dinámicas del quehacer grupal. No se trata de un conocimiento racional de los derechos desde la norma, sino de la apropiación de estos en la práctica cotidiana.

Esta visión crítica de los derechos humanos sirve de sustento teórico para la validación de una metodología que en la práctica artística se posiciona contra los privilegios asignados a unos cuantos dueños del saber literario, y así crear en colectivo un discurso estético que prima todas las posibilidades de expresión a través de los recursos metafóricos e imaginativos.

\subsubsection{Una estética activa y grupal}

Ante la propuesta de un discurso moralista y sublime del arte, se plantea la posibilidad de hacer del este una vivencia reivindicadora, si bien estética también y principalmente, epistemológica, y crítica en donde los parámetros establecidos en el nivel político y moral no tengan en sí mismos un deber ser más que el hecho de generar un espacio para la voz de las personas que han sido silenciadas sistemáticamente. Es decir, se plantea la posibilidad de la creación artística alejada de la reproducción de un discurso hegemónico que dirige el quehacer artístico como herramienta sistémica, para la prevalencia de lo socialmente (cultural y moral) establecido. 
Así tomamos parte de la aseveración sobre la estética de lo de oblicuo de Ana del Sarto en Una estética de los residuos: Nelly Richard y la crítica cultural en chile:

En consecuencia, lo estético permite intervenir el paisaje social, cultural y político (actualmente, aplanado por la lógica dominante de la transparencia) y construir una mirada crítica: esa es precisamente "la dislocación estética y la mirada política [que propone] la crítica cultural". Su objetivo es revelar lo transparente, lo completamente naturalizado por el sentido común como un artificio más de los lenguajes y, a través de mayores torsiones y giros retóricos, opacar los referentes hasta multiplicar sus significados. Esa es la consigna de las estéticas de la oblicuidad. (Del Sarto, 2008, p. 161).

Lo que se propone no es una revolución únicamente formal de los procesos artísticos es decir no se proyecta como fundamento contra hegemónico, una vanguardia o revolución en lo estético, aunque estas son o podrían ser una manifestación del fondo epistemológico que se defiende. La base principal de esta idea se plasma en la posibilidad de abandonar la idea de qué el arte es para unos cuantos privilegiados con dones o talentos específicos que además deben pasar por procesos formales de educación, para poder ser llamados artistas. Esta propuesta, por tanto, invita a la generación de espacios, momentos y posibilidades de creación artística como medio no formal de empoderamiento, que además emprenda el camino del autoconocimiento y la experiencia de creación artística, como medio para la instauración de conocimiento.

\subsection{Lo colectivo}

Se entiende por hechos colectivos, todos aquellos actos o procesos que asuman entre sus razones de ser, el existir por y para la construcción intersubjetiva de conocimientos. De manera que los procesos socioculturales y artísticos adscritos o que echen mano de esta metodología serán aquellos que entiendan que para que el arte reivindique modos de vida y dignifique a los sujetos, no debe ser visto de manera concreta el producto, ni de manera idealista el proceso de inspiración como acto sublime, sino que este tipo de arte se planta como un proceso intersubjetivo en donde las personas participantes crean en un suscitado momento espacio-temporal, todo aquello que el medio y los participantes de este (emociones, vínculos y vivencias) estimulen para la creación artística.

Lo colectivo deviene a su vez del sentido libre de interpretación que dan las personas creadoras, así como los "receptores" de la "obra", quienes haciendo uso de sus facultades lingüísticas y estéticas crean el "producto final" en abstracto, uno inacabado, abierto a la posibilidad de interpretación de sus receptores. La 
experiencia estética es colectiva, aun cuando esta no se asuma como tal, en el tanto cada interpretación es a su vez una nueva forma del producto.

\subsubsection{El proceso creativo en colectividad}

El proceso conlleva cargas epistemológicas y culturales y por tanto, se encuentra a su vez permeado de los saberes emocionales y semánticos de las personas que de él participan. En el nivel didáctico, se trata de llevar a un extremo creativo la propuesta epistemológica de la investigación temática de Paulo y Elza Freire la cual "es dialéctica, busca un conocimiento científico de la realidad, no un conocimiento puro y real de ella; tiene como objetivo el estudio de la creación cultural de las comunidades" (Bosco, J., 1975 p. 12).

Bajo la afirmación de que el ser humano es creador de cultura y lenguaje como expresión de su visión de mundo, se rescatan los universos vocabulares de las personas participantes de las propuestas artísticas, no solo para el reconocimiento cultural de las personas, y la incorporación de un aprendizaje específico, sino que también, ese rescate de los universos tiene la intención de generar a través de la poesía, incalculables repercusiones semánticas, tanto en los creadores como en los receptores de la obra.

La propuesta da prioridad al proceso creativo y no al producto final, es decir no se plantea una alternativa solo en los productos generados, sino principalmente, una maximización de los procesos cognitivos de la creación en las etapas de exploración creativa y gestación de los resultados finales (que pueden o no existir como producto de mercado). Así, se introduce el hecho de que esta nueva forma de vivenciar el arte es principalmente colectiva y es la experiencia con otros creadores la que enriquece de manera especial los procesos artísticos. Se plantea por tanto, que en la riqueza de los conocimientos previos de cada persona y en la congregación de estos, se hace de los procesos artísticos experiencias personales, cargadas de valor epistemológico, psicológico y semántico. A diferencia de las producciones artísticas convencionales son estas individuales o colectivas, los procesos de creación no tienen como objetivo el producto final, sino la experiencia misma de la creación.

Estos son por tanto, procesos colectivos artísticos y espacios para la dignificación de las personas, en tanto: a) se reconocen sus orígenes y saberes culturales, b) los saberes y los orígenes culturales son rescatados por los participantes como base de sus quehacer artístico, c) existe una autovaloración subjetiva e histórica por parte de las personas participantes, d) en la colectivización de los productos artísticos hay un reconocimiento intersubjetivo, por parte de los participantes a través de los procesos dialógicos, e) el reconocimiento cultural y de las subjetividades encuentra 
posibilidades creativas de expansión y por tanto, el proceso de dignificación tendrá límite en los receptores posibles.

\subsection{Lo performático}

Por performático se comprende en el presente trabajo la posibilidad de adjetivar todas aquellas acciones que se planteen a propósito y voluntariamente estéticas, y que además hacen un ejercicio consciente por la expresión de algún o algunos determinados discursos comunicados a través de los diferentes lenguajes artísticos. Por performance no se entiende únicamente lo derivado del anglicismo, es decir no se ve únicamente en el sentido de espectáculo o presentación. Lo performático se manifestaría en la expresión de aquella capacidad con la que cuentan los sujetos como seres creativos, para irrumpir la realidad a través del arte, en afán de la apropiación del espacio y a favor de una experiencia estética. En resumen, un acto performático es todo aquel que a través del lenguaje artístico propone una experiencia estética que irrumpa con la realidad tempo-espacial. Pero aunado a la experiencia misma, lo performático tiene un carácter político fundamental. Los contextos sociales de la contemporaneidad son infinitamente opresores, las reglas sociales, estatales y de mercado son cada vez más alienantes y rígidas para con la libertad humana, y es por tanto que los seres humanos se ven cada vez más limitados a la toma espontánea de espacios en donde sus facultades creativas no estén asociadas a lógicas productivistas.

Es por eso, que una metodología dignificatoria y que haga manifiesto el accionar humano por sus derechos debe, francamente, proponerse como una metodología performática, que irrumpa la realidad de manera dialéctica entre los saberes culturales y artísticos, y que además prime los conocimientos sensibles, sin otro objetivo más que la vivencia como manifestación de la libertad, para la dignificación de quienes de ella participan. Lo performático es entonces una no instrumentalizada forma de hacer política, gracias a su carácter espontáneo que le permite hacer uso de las formas, sin serlas o depender de ellas. En el entendido de política como ejercicio ciudadano lo performático desafía la estructuración moderna del poder, flexibilizando la comunicación de las ideas más allá de los alcances racionales, para hacer de la experiencia política una práctica a su vez sensible.

\section{Conclusiones}

A modo de conclusión puede afirmarse que el desarrollo del proyecto Liberando Ecos apostó a una metodología radicalmente performática, colectiva y contrahegemónica en la que los participantes, comprendidos por su condición en el 
proceso como cuerpos-dignificantes, ejercían de manera voluntaria y consciente sus capacidades creativas a partir de un lenguaje artístico.

El desarrollo del proceso primó la experiencia estética y epistemológica, la cual a su vez validó el modo de vida y saberes de los participantes por encima de la materialización del arte, ya sea por la creación de un producto artístico final y concreto, o bien por la obtención de recursos económicos.

La experiencia artística de la metodología del proyecto Liberando Ecos, es además una constante en el tiempo y no acaba con el hecho creativo (la creación colectiva), ni con el producto (la obra), pero tampoco con su presentación (el espectáculo). Las repercusiones simbólicas crearon transformaciones emocionales en los sujetos participantes, que en el caso de Liberando Ecos significaron la evolución de personas privadas de libertad a autores de un libro, el cual no es objeto sino medio.

Para ejemplificar esta transformación pueden observarse las metáforas del poema "Olvidados" de Jonathan Cubillo Mora uno de los autores del libro Cementerio de los vivos:

\section{Olvidados}

¿Qué hacen hombres cubiertos, cubiertos de armaduras?

Sus rostros reflejan todas las desgracias de una vida.

Inmersos en la cápsula del tiempo.

En la noche fría del inmenso silencio

se escuchan aullidos del alma, inquebrantables, corazones olvidados escondidos en las sombras de la muerte.

(Álvarez, 2016, pág. 32).

Liberando Ecos permitió que se ejercieran los Derechos Humanos de manera vivencial, utilizando medios artísticos y grupales para la expresión de las necesidades y las voluntades, de manera que mediante la poesía se hiciera efectivo el reclamo por las injusticias, tal y como lo expresa el poeta los "hombres cubiertos de armadura", "aúllan", gritan, reclaman ya no "En la noche fría del inmenso silencio", sino en los recitales realizados en los teatros, bibliotecas, universidades, pero especialmente, en las repercusiones subjetivas de cada lector o lectora del libro, estos hombres ya no serán olvidados. 


\section{Referencias}

Álvarez, O. B. (2016). Cementerio de los vivos. San José: Circulo literario vertedero satélite.

Bezanilla, J. (2011). Sociometría: un método de investigación psicosocial. México D. F.: PEI Editorial.

Bosco, J., Arnulfo, M., Reyes, V. (1975). Metodología de la investigación temática: supuestos teóricos y desarrollo. Chasqui: Revista latinoamericana de comunicación. Núm. 10. CIESPAL. Ecuador.

Carnacea, Á. R. (2012). Arte, intervención y acción social. Hacia la construcción de comunidades inclusivas. Congreso de culturas vivas comunitarias. (Pp. 1-10). San José.

Castro-Gómez, S., Grosfoguel, R. (2007). El giro decolonial: reflexiones para una diversidad epistemológico más allá del capitalismo global. Bogotá: Siglo del hombre.

Colom, A. J. (2005). Continuidad y complementariedad entre la educación formal y no formal. Revista de educación (338), 9-22. Madrid, España.

De Sousa Santos, B. (2009). Una epistemología del sur. La reinvención del conocimiento y la emancipación social. México D. F.: CLACSO Ediciones / Siglo XXI Editores.

Del Sarto, A. (2008). Una estética de los residuos: Nelly Richard y la crítica cultural. En Chile. Ohio, Estados Unidos.: Ohio State University.

Garrido, E. (1978). Jacob Levi Moreno. Psicología del encuentro. Madrid: Sociedad de Educación Atenas. S. A.

Gil, F. (2016). Decálogo pedagógico de la educación social en prisión. Revista de educación social (22). Barcelona, España.

Herrera, J. (2008). La reinvención de los derechos humanos. Andalucía: Editorial Atrapasueños.

Howie, P. (2014). Using sociodrama to explore and engage with complex thematic metaphors. Gestalt Journal of Australia and New Zealand, 11(1), 78-90.

Moreno, J. (1993). Psicodrama. Buenos Aires: Editorial LUMEN.

Moreno, J. (1972). Fundamentos de la sociometría. Buenos Aires: Paidós.

Moreno, J. (1977). El teatro de la espontaneidad. Buenos Aires: Editorial Vancu.

Morin, E. (2002). La cabeza bien puesta. Repensar la reforma. Reformar el pensamiento. Buenos Aires, Argentina: Nueva Visión. 
OEA (2016). Relatoría sobre los Derechos de Personas Privadas de Libertad realiza visita a Costa Rica. Washington, D. C.: OEA.

Renes, V. (2007). Realidad, pensamiento e intervención social. Documentación socia: Revista de Estudios Sociales y de Sociología Aplicadal (145), 11 - 35.

Reyes, G. (2006). Psicodrama: paradigma. Chile: Editorial Cuatro Vientos. Santiago, Chile.

Síntes, R. (1995). Aquí y ahora: El psicodrama. Uruguay: Ediciones Multiplicidades.

Síntes, R. (2008). La terapia de los dioses caídos. Uruguay: Psicolibros.

Talavera, A. (2010). Teatro penitenciario en el centro de readaptación social de Morelia Michoacán: un análisis de las identificaciones construidas a través del escenario. Morelia: UMSNH.

Trilla, B. (1993). Otras educaciones. Animación sociocultural, formación de adultos y ciudad educativa. Barcelona: Anthropos.

Vivos, T. L. (Noviembre de 2016). ¿Qué significa ser escritor? (S. B. Zúñiga, entrevistador) Recuperado el 21 de enero de 2018, de https://www.youtube.com/channel/ UCKvRYfmTOMAmRo1B7X77PYg

Recibido: 4/12/2018

Aceptados: 2/5/2019 
